\title{
(Des) disciplinarização da avaliação: uma experiência na Educação a Distância
}

\section{(Un) assessment of disciplining: an experience in Distance Learning}

\author{
Rita de Cássia M. T. Stano, Alessandra Rodrigues \\ Universidade Federal de Itajubá, Brasil
}

\begin{abstract}
Resumo
Este trabalho reflete sobre o processo avaliativo de um curso a distância partindo do pressuposto de que avaliação é construção ativa e crítica. O curso realiza avaliação presencial ao final de cada módulo, em dois momentos: reflexão orientada individual, a distância e em pequenos grupos, presencialmente. As atividades visam a averiguar a capacidade de inter-relação de conceitos, teorias e práticas estudadas em contextos ficcionais apresentados avaliando competências e habilidades centrais para o exercício profissional. Percebe-se o desenvolvimento da capacidade dos alunos de reagrupar conceitos e teorias estudados em contexto prático-ficcional. Ocorre, assim, uma (des) disciplinarização no processo de realização dessa avaliação interdisciplinar.

Palavras-chave: avaliação, educação a distância, formação profissional.
\end{abstract}

\begin{abstract}
This work reflects a practice evaluation process of a distance learning course on the assumption that evaluation is active and critical construction. The course carries out on-site assessment at the end of each module, in two stages: individual guided reflection, distance and in small groups, face. Aim to ascertain the interrelation ability of concepts, theories and practices studied in fictional contexts presented evaluating skills and core skills for professional practice. One sees the development of students' ability to regroup concepts and theories studied in practical-fictional context. There is an (un) disciplining the process of an interdisciplinary evaluation.

Keywords: evaluation, distance education, vocational training
\end{abstract}

\section{Introdução}

Avaliar é uma atividade inerente ao ser humano em seu movimento de construir significados acerca do mundo em que vive. No âmbito educacional, a avaliação assume um caráter importante por ser o ponto de partida para a reorganização dos processos de ensinar e de aprender.

Parte-se do pressuposto de que avaliação é conquista e construção, faceta ativa e crítica, onde a recriação da ação ocorre pelo diálogo."As pessoas têm que se sentir efetivamente participando, aprendendo a participar e, para tal, compreendendo a realidade onde estão, a fim de que passem do sentir para o compreender e agir" (ABRAMOWICZ, 1990, p. 38).

Este trabalho analisa os resultados de quatro avaliações, ocorridas no primeiro e segundo módulos de um curso de especialização a distância buscando indícios de um processo de (des) disciplinarização da avaliação com vista à construção coletiva, reflexiva, crítica e contextualizada do conhecimento.

\section{Método}

A (des)disciplinarização via avaliação é resultante de um exercício conjunto de reflexão e prática acerca do processo avaliativo instituído no curso de especialização a distância em Gestão de Pessoas e Projetos Sociais, oferecido desde 2007 por uma universidade pública brasileira.

O referido curso está organizado em 4 módulos, a saber: a) Núcleo Básico, com disciplinas que têm por objetivo garantir conceitos básicos acerca dos processos de gestão; b) Núcleo Gestão de Pessoas, que trabalha com as especificidades da gestão organizacional; c) Núcleo Gestão de Projetos Sociais, que enfoca aspectos específicos de Projetos Sociais. Ao final de cada módulo, há um encontro presencial em que se realizam avaliações interdisciplinares.

As avaliações interdisciplinares são atividades propostas e desenvolvidas em dois momentos: um momento individual, que prepara os alunos para o encontro e para o segundo momento, de realização da atividade avaliativa desenvolvida em pequenos grupos.

Entendemos que as avaliações são interdisciplinares porque não se baseiam nas especificidades de cada disciplina, mas visam a averiguar a capacidade de inter-relação de conceitos, teorias e práticas estudadas em cada conteúdo, em contextos apresentados e que são, naturalmente, eivados de interdisciplinaridade. Assim, concordamos com Fazenda (2013, p. 29) quando a autora afirma que a "interdisciplinaridade é definida amplamente como uma interação existente entre duas ou mais disciplinas. Essa interação pode ir da simples comunicação das ideias até a integração mútua dos conceitos chaves da epistemología, da terminologia, dos procedimento, dos dados e da organização da pesquisa e do ensino relacionando-os".

Descrição da Construção do Processo Avaliativo

As questões propostas em cada encontro presencial, referentes a cada módulo do curso, são elaboradas cuidadosa e criativamente pelos professores do módulo que será avaliado, a fim de propiciar modos de aplicação efetiva do que foi estudado em situações fictícias, porém, correspondentes a determinadas realidades do mundo do trabalho.

Há uma variedade de temas e de propostas avaliativas, tais como solicitar: a) elaboração de programas fictícios de rádio; b) organização hipotética de cursos de capacitação em empresas; c) estudos de casos específicos; d) criação de projetos sociais para um contexto específico vinculado às cidades onde se situam os polos de apoio presencial ao curso; e) planejamento 
de congressos, cursos de capacitação fictícios na área de Gestão de Pessoas ou de Projetos Sociais, etc. Tais formas de avaliação permitem verificar competências e habilidades centrais para a formação de um especialista em Gestão de Pessoas e de Projetos Sociais, bem como a capacidade de aplicação de conhecimentos em situações práticas.

A correção dos trabalhos elaborados pelos alunos nesses processos avaliativos ocorre de forma também interdisciplinar, em que todos os professores, juntos, efetuam leituras e análises conjuntas. Tal correção parte de um conjunto de critérios previamente estabelecidos, considerando: a) uso de terminologia adequada; b) articulação de teorias das diversas disciplinas numa síntese otimizada na prática; c) criticidade no uso de ferramentas específicas para aplicação prática solicitada.

A seguir, apresentamos as quatro avaliações a partir das quais realizamos este estudo:

1) Avaliação Interdisciplinar Módulo 2 (Parte I individual e a distância)

Você está recebendo um link. A partir do que assistiu e baseando-se nas disciplinas do Módulo 2, elabore material para refletir junto aos seus funcionários (hipoteticamente você é líder de uma empresa) contendo 3 panoramas:

Panorama 1: os sentidos da "evolução dos homens na sociedade" conforme parte 1 do vídeo assistido (O que somos, como estamos...);

Panorama 2: o papel das organizações produtivas no cenário "evolutivo" das sociedades humanas (as organizações como estão...);

Panorama 3: a utopia necessária: possibilidades de mudança nas organizações de acordo com o discurso de Chaplin (as organizações como devem ser...).

As seguintes categorias que deverão estar presentes na descrição dos panoramas: ser humano, relações interpessoais, trabalho, trabalho em equipe, ética, liderança, gestão de pessoas, qualidade de vida. Cada panorama deve ser descrito em duas laudas.

2) Avaliação Interdisciplinar Módulo 2 (Parte II coletiva e presencial)

Primeiro momento: Apresentação dos objetivos do encontro e divisão das equipes conforme imagens de paisagens escolhidas e distribuídas pelos espaços da sala de aula (o aluno deverá escolher o lugar em que ficará de acordo com a figura que mais o atrair). Formação de dez equipes com 5 integrantes. Cada equipe receberá duas revistas.

Segundo momento: Explicação e esclarecimentos acerca da atividade que deverá ser realizada.

Terceiro momento: Elaborar Panoramas (1. o que somos, como estamos; 2. as organizações como estão; e 3. as organizações como devem ser) por meio de painel gráfico utilizando figuras e ilustrações das revistas, desenhos e slogans.

Quarto momento: Elaboração do trabalho proposto.

Quinto momento: Organização dos painéis (na parede próxima à equipe).

Sexto momento: Apresentações das equipes.
Encerramento: Avaliação do módulo e do encontro do dia.

3) Avaliação Interdisciplinar Módulo 1 (Parte I individual e a distância)

Em época de festivais, que tal planejarmos um Festival intitulado "Organizações 2012"?

Qual seria o público-alvo? Gestores

Objetivo Geral: incentivar mudanças na gestão das organizações, apresentando as principais possibilidades/conceitos em estudo.

Duração: duas noites intensivas para abarcar todas as temáticas (por disciplina).

Imaginemos você preparando a programação: temas e conceitos a serem trabalhados, autores/estudiosos a serem convidados.

Baseando-se em todas as disciplinas do Primeiro Módulo (Fundamentos de Empreendedorismo, Gestão do Conhecimento e Sistemas de Informação, Aprendizagem e Processos Criativos, Cultura e Identidade nas Organizações, Fundamentos Antropológicos da Cultura Brasileira, Ética e Responsabilidade Social nas Organizações, Metodologia de Pesquisa Científica, Tendências Contemporâneas de Gestão Organizacional), elabore um documento contendo:

- Principais temas que seriam abordados no evento;

- Conceitos e principais teorias para mudança de postura nas gestões organizacionais;

- Autores que podem ser consultados (bibliografia).

Observação: entrega deste "Documento" no dia do encontro presencial, impresso. Não basta apresentar os títulos. É preciso que os principais conceitos estejam explícitos neste documento, como se fosse uma apostila do evento.

4) Avaliação Interdisciplinar Módulo 1 (Parte II coletiva e presencial)

Primeiro momento: Preparação do Festival. O grupo deve definir os objetivos e metas.

- A meta é o objetivo final do seu evento, que oferece um roteiro completo para o seu planejamento. Normalmente, um evento pode ter vários objetivos e metas. Considerando como objetivo geral: incentivar mudanças na gestão das organizações, apresentando as principais possibilidades/conceitos em estudo. Duração: duas noites intensivas para abarcar todas as temáticas (por disciplina).

- Estabeleçam a programação (com cronograma) contendo os temas, conferencistas, atividades como mesa-redonda, painéis etc. Aproveitem os trabalhos individuais.

- Criem materiais de marketing ou promocionais. Os organizadores devem fornecer informações básicas sobre o evento. A mensagem deve ser tão simples quanto possível, sendo relacionados data, hora, detalhes de contato sobre o evento e o local etc. Usem materiais diversos como panfletos, cartazes, homepage.

Segundo momento: Trabalho nas esquipes.

Terceiro momento: Apresentação dos trabalhos dos grupos. 
Quarto momento: Avaliação do módulo e do encontro do dia.

\section{Procedimentos de análise dos dados}

Os dados foram analisados qualitativamente e consideraram tanto os trabalhos produzidos pelos alunos quanto as observações participantes (GONDIM, 2003) realizadas pelos profesores e tutores durante o processo de elaboração e realização das atividades avaliativas.

Os critérios que orientaram as análises tiveram como base os elementos norteadores das correções feitas pelos docentes, já mencionadas anteriormente: uso de terminología adequada, articulação de teorias das diversas disciplinas envolvidas e criticidade.

\section{Resultados}

As atividades avaliativas mostram, relativamente aos critérios pré-estabelecidos:

a) uso de terminologia adequada: os trabalhos elaborados pelos alunos nas avaliações efetuadas mostram uso correto de terminologia, tanto quando apresentam teorias explicativas e justificadoras para a aplicação na situação fictícia considerada, quanto na exposição de ferramentas usadas para a consecução da ação requerida;

b) articulação de teorias das diversas disciplinas numa síntese otimizada na prática: tal aspecto é o mais destacado nos trabalhos realizados pelos alunos no processo avaliativo, tanto nas produções individuais quanto no momento coletivo, em que ocorre a (des)disciplinarização, sem destaques para esta ou aquela disciplina, mostrando a apropriação de estudos e teorias contextualizadas, apoiando o sentido de uma síntese teórico-prática que concretiza o aprendizado;

c) criticidade no uso de ferramentas específicas para aplicação prática solicitada: alguns trabalhos elaborados pelos alunos apontam para um movimento de escolha consciente de ferramentas que se coadunam com o que o contexto ficcional exige, descartando as ferramentas que não correspondem a uma visão ampla e humanizadora de gestão.

Numa abordagem mais ampla do processo, a experiência de elaboração e aplicação das atividades avaliativas mostra o compromisso assumido com a própria realidade, desnudando a experiencia dos sujeitos envolvidos na avaliação, revelando-a enquanto obra e construção coletiva. Ocorre, pois, uma (des) disciplinarização correspondente às exigências da inserção do profissional no mundo do trabalho.

Percebe-se uma avaliação com caráter interdisciplinar e político favorecendo releituras, interações teórico-práticas e reaprendizagem global, caracterizando que a interdisciplinaridade na avaliação se concretiza na (des) disciplinarização dos saberes. Nesse sentido, "A consciência se reflete e vai para o mundo que conhece: é o processo de adaptação. A consciência é temporalizada. O homem é consciente e, na medida em que conhece, tende a se comprometer com a própria realidade" (FREIRE, 1979, p.39).

Percebeu-se também o desenvolvimento da capacidade dos alunos de reagrupar conceitos e teorias estudados nas disciplinas de cada módulo em um contexto articulado com a prática.

\section{Discussão}

Os resultados das experiências avaliativas mostram que a educação a distância apresenta-se como um novo ambiente de aprendizagem que passa a exigir habilidades, competências e atitudes diferenciadas de alunos e professores, de acordo com conceitos já apresentados por Perrenoud (1993) acerca de competências e habilidades. Nesse novo ambiente, desmodelizam-se a avaliação e suas modalidades, desarticulam-se certezas e instala-se uma interatividade, que, apesar de denominada, "a distância", pode se constituir em uma interatividade de novo tipo, porque mais próxima de atitudes como diálogo, comunicação necessária e insubstituível e produção mais autoral de textos.

$\mathrm{O}$ aprendiz aqui deve ser entendido como um ser em aberto, um ser em devir porque puro projeto que se reinventa e reinventa o mundo a partir de sua ação e de seu exercício cognitivo, sendo, pois, um cidadão em construção. Nesse sentido de construção permanente, o professor também se apresenta como co-construtor de mundos e, por isso, de conhecimento (GIROUX, 1997).

A avaliação, longe ser considerada como um fim em si mesma, deve ser vista como meio de favorecer o encontro de sujeitos que se constroem e constroem saberes. Demo (2002) corrobora tal assertiva ao expor que motivar para o aprender (e para o avaliar), há que não focar apenas o racional, mas a "envolvência".

Importante ressaltar que, na abordagem construtivista, o conceito de mediação é central para a compreensão do processo de avaliação da aprendizagem. Mediar é intervir numa relação para a promoção da mudança. Assim, na relação do sujeito que aprende com o material a ser aprendido, entra o papel do professor como mediador, de acordo com Freire (1996). Essa mediação se faz por meio da palavra, do diálogo, da tecnologia, do texto. Dessa forma, a mediação do professor no processo de educação a distância e, especificamente, no processo avaliativo, se reconfigura nos três "C"s, a saber: comunicação, colaboração e criatividade. Uma presencialidade docente que se faz na mediação das atividades, das propostas, das indagações, da avaliação como processo.

Nesse contexto, a Educação a distância precisa ser devidamente questionada no sentido de apreender o seu alcance. E tal apreensão dependerá do conceito que se tem de aluno e de aprendiz. Se considerar o aprendiz como passivo e mero depositário de conceitos e teorias, a educação a distância não irá além de meio para treinamento. Mas, enquanto possibilidade de verdadeira formação, o sujeito passa a ser considerado como ativo e responsável pelo seu próprio aprendizado. Assim, o aprender é não mera reprodução, mas deve ser visto enquanto fenômeno (re)construtivo, pois o ser humano capta a realidade, não mecanicamente ou como representação direta, mas, como sujeito, a reconstrói e a incorpora como habitus, segundo Bourdieu apud Nogueira e Nogueira (2004).

Por isso, os estudos vêm chamando a atenção para um 
novo tipo de relação pedagógica exigido para o êxito da educação a distância e, consequentemente, isso se reflete no processo avaliativo. Uma relação entre professor-aluno baseada na confiança na capacidade do outro, principalmente do aluno em assumir o seu próprio processo de aprender.

Assim, inaugura-se a co-responsabilidade neste novo contexto de aprendizagem em que professor e alunos equilibram tempo, ritmo, modos de aprender (e de ensinar!) e mecanismos de autoavaliação. Nesse sentido, o aluno, visto como sujeito, a partir do que sabe, é capaz de interpretação própria, elaborando-se na elaboração do novo.

São desafios postos a uma avaliação que ainda se percebe um pouco engessada frente a uma maneira outra de exercer o "controle" sobre o processo de aprendizagem. Efetuar uma avaliação também mediatizada, na vertente construtivista, em ambientes virtuais que se expandem e se alongam para os encontros presenciais, sugere a dialogicidade e a consideração ao erro enquanto caminho de elaboração própria. Ou seja, ao professor cabe rever o seu papel e a sua atitude que, de acordo com Moreira, Alves e Garcia (2006), estão menos postos como autoridade e poder e mais como co-participantes de construção de conhecimento num ambiente que possibilita outras maneiras de aproximação com o aluno.

Não mais somente olhares e feições, mas expressões escritas e atentas que permearão os diálogos, as dúvidas, as incertezas e as respostas provisórias. $\mathrm{O}$ virtual pode não oferecer, em algunas situações, a riqueza das aulas em ambientes físicos e pontuais, mas pode se constituir um outro e também possível modo de se promover o encontro e, por isso, o aprendizado. Amplia-se aqui o conceito de avaliação para o sentido do encontro, da partilha de saberes e dúvidas em que variadas linguagens garantem a comunicação. Professores e alunos como investigadores, articuladores e parceiros de novos conhecimentos. Os primeiros, criando modos outros de efetuar a avaliação e os segundos, buscando novas soluções para contextos em construção. São novas racionalidades e novos estímulos perceptivos que precisam ser considerados e conhecidos para que a avaliação seja realmente eficaz na educação a distância.

Desse ponto de vista, somos todos (professores e alunos) sujeitos aprendentes buscando, como aponta Fazenda (2013), fundamentar a práxis, seja pelos diálogos da academia, seja pelo diálogo com os pares no cotidiano de trabalho. Por esse viés, a avaliação se dá no entrecruzamento de saberes e fazeres dos sujeitos, estabelecendo-se como mais um elemento no processo de construção do conhecimento e não como um fim em si mesma.

Inventar novos caminhos de problematização, atualizar conhecimentos, instituir o aprender a aprender em processos simultâneos individuais e grupais são maneiras de elaborar uma nova e também válida interdisciplinaridade via processo avaliativo de (des)disciplinarização. Porque, a presença do professor, mais que no corpo físico, está em seus modos, em suas palavras, em seu encantamento pelo saber em todo e qualquer ambiente onde se encontra o outro. E, nesse encontro, professores e alunos vão construindo modos novos de se fazer educação, num estilo reconstrutivo de avaliar o aprendido.

A educação a distância deve ser pensada e construída por um conjunto de profissionais que, formando equipes multidisciplinares, possam amparar o processo educativo e otimizá-lo de acordo com os objetivos postos atualmente para a educação. Novos papéis, novos conceitos, novas propostas de aprender e de ensinar devem ser feitos. Á avaliação cabe, pois, a sustentação teórico-prática desse movimento e, no contexto da educação a distância, que ela possa ser um caminho para se fazer educação assumindo, a partir do aporte construtivista, alguns desafios como:

- a criação de novos modos de garantir e promover a interação e interiorização de conhecimentos;

- o desemvolvimento de mecanismos de promoção do pensamento divergente e convergente (apreensão e criação);

- a busca por maneiras de garantir significados e interconexões entre conceitos, práticas e valores;

- a criação de equilíbrio entre emocional, racional, ético, pessoal e social;

- a garantia do binômio equilibrado entre teoria e prática;

- a efetuação de um planejamento avaliativo flexível e aberto;

- a integração de metodologias avaliativas; e

- a promoção, via avaliação, da aprendizagem cooperativa.

\section{Referências}

Abramowicz, M. (1990). Avaliação de aprendizagem: como trabalhadores-estudantes de uma faculdade particular noturna veem o processo em busca de um caminho. Tese de doutorado. Faculdade de Educação, Pontifícia Universidade Católica de São Paulo, São Paulo, Brasil.

Demo, P. (1993). Desafios Modernos da Educação. Petrópolis: Vozes.

Fazenda, I. C. A. (2006). Formação de Professores: dimensão interdisciplinar. En: Fazenda, I. C. A. \& Ferreira, N. R. S. (Eds.) (pp. 29-33). Formação de docentes interdisciplinares. Curitiba: CRV.

Freire, P. (1979). Educação e mudança. 2. ed. Rio de Janeiro: Paz e Terra.

(1996). Política e educação. São Paulo: Cortez.

Giroux, H. A. (1997). Os professores como intelectuais: rumo a uma pedagogia crítica da aprendizagem. Porto Alegre: Artes Médicas.

GONDIM, S. M. G. (2003). Grupos focais como técnica de investigação qualitativa: desafios metodológicos. Paidéia, 2003, vol. 12, n. 24, 149-161. httpwww.revistas.usp.brpaideiaarticleviewFile46653504 09.

Moreira, A. F. B., Alves, M. P. C. \& Garcia, R. L. (Eds.). (2006). Currículo, Cotidiano e Tecnologias. Araraquara: Junqueira e Marins.

Nogueira, M. A. \& Nogueira, C. M. M. (2004). Bourdieu e a Educação. Belo Horizonte: Autêntica.

Perrenoud, P. (1993). Práticas Pedagógicas Profissão Docente e formação: perspectivas sociológicas. Lisboa: Dom Quixote. 